ISSN 1991-8631

Original Paper

http://indexmedicus.afro.who.int

\title{
Biosorption of copper and zinc from aqueous solution by bamboo biomass in batch and column studies
}

\author{
E. Afamefuna OKORONKWO ${ }^{1 *}$ and Kelechi EBISIKE ${ }^{2}$ \\ ${ }^{1}$ Department of Chemistry, Federal University of Technology, PMB 704 Akure, Nigeria. \\ ${ }^{2}$ Engineering Materials Development Institute, Akure, Nigeria. \\ ${ }^{*}$ Corresponding author, E-mail: afamex@yahoo.com, Tel: +2348034047318
}

\begin{abstract}
In the present work, the use of bamboo biomass for copper and Zinc biosorption was studied in batch and column processes. The effects of equilibrium $\mathrm{pH}$, contact time and the presence of Magnesium and Calcium interfering ions on the sorption of these metals were investigated. Experimental results showed that the Bambusa vulgaris biomass was effective in removing copper and Zinc ions from aqueous solutions. Sorption of the metals was dependent on equilibrium $\mathrm{pH}$, as maximum removal was attained at $\mathrm{pH}$. The Langmuir isotherm model fitted the experimental data. The biosorption of copper and zinc on bamboo biomass was rapid and equilibrium was attained within $15 \mathrm{~min}$. The sorption kinetic data revealed that the biosorption of copper and Zinc on this biomass followed pseudo-second order model.

(C) 2010 International Formulae Group. All rights reserved.
\end{abstract}

Keywords: Sorption, bamboo, Biomass, isotherms, interference, modification, fixed-bed column.

\section{INTRODUCTION}

The presence of heavy metal ions in surface, ground and industrial waste water has continued to be a global environmental problem. Metals such as copper, iron, zinc, nickel, cadmium, lead, mercury etc are known to be significantly toxic. Unlike organic pollutants, these metal wastes are not biodegradable as such increasing concentration in water constitute severe health hazard (Larous et al., 2005). These metals come from various sources such as wastes from metal plating, mining, tanneries, painting, smelting, glass ceramic, metal finishing, storage batteries, petroleum, paper and pulp industries (Bailey et al., 1999; Low and Lee, 2000; Figueira et al., 2000;
Keshkinkan et al., 2003) etc. There is enormous contribution from agricultural sources through the use of fertilizers and fungicides. Copper is widely used however excessive intake by man could lead to irritation of the central nervous system and mucosal cell, kidney or liver damage when accumulated in these organs. The toxicity impact of copper is reported to be $\mathrm{pH}$ dependent with toxic effects in fish at very low pH (Sharma et al., 1992). Incidence of stomach cancer in human has been found in regions where $\mathrm{Zn}$ : $\mathrm{Cu}$ ratio of the soil exceeded certain threshold limits. Problems attributable to the presence of poisonous metals in drinking water have necessitated stringent conditions and regulations as well as 
increasing demand for newer technologies for water treatment.

Conventional techniques for metal removal currently in use include: ion exchange, chemical precipitation, reduction, filtration, membrane technology, solvent extraction, electro-floatation, reverse osmosis to mention a few. These methods are not only considered expensive but ineffective for the removal of lower concentrations of metals (Sternberg and Dom, 2002; Ahluwalia and Goyal, 2007), hence there is need for new methods to reduce heavy metal concentration to environmentally acceptable levels at affordable cost. Adsorption processes using natural adsorbents or agricultural waste materials are fast gaining acceptance as new alternatives for waste water treatment for obvious reasons of cheaper cost and easy handling (Magat et al., 2006; Volesky, 1994). Some of the biomaterials and agricultural byproducts studied include bacteria, fungi, algae, peat carrot residue, wood, pine bark, soy bean, peanut shells, rice husk, saw dust, orange peel, pomegranate peel, sun flower etc (ElAshtoukhy et al., 2008; Aksu 2001; Valdman et al., 2001; Mehta and Gaur, 2005; Nasernejad et al., 2005; Alpana et al., 2007; Okoronkwo and Olasehinde, 2007). Biological materials contain numerous potential binding sites and functional groups that can complex with metal ions. Such groups as hydroxyl, carboxyl, phenol and phosphates had been identified (Abu Al-Rub et al., 2004; Kuyucak and Volesky, 1989).

The aim of this work was to study the adsorptive capacity of bamboo biomass for the removal of copper and zinc from aqueous solutions and the objectives were to monitor the effects of $\mathrm{pH}$, contact time and the presence of interfering ions on the process. Bamboo is a group of woody perennial evergreen plant in the true grass family Poaceae, subfamily Bambusoideae, tribe Bambuseae. Some of its members are giant bamboo, forming by far the largest members of the grass family. Bamboo tissue is noted for its high content of cellulose, hemi cellulose and lignin, both having high capacity to bind metal cations due to abundance of hydroxyl group (Fengel and Shao, 1984). It grows widely in the southern part of Nigeria and is used extensively in gardens as stakes, as a building material and as a source of fire for cooking. Due to its availability, finding alternative use for this plant will be economically beneficial.

\section{MATERIALS AND METHODS \\ Materials}

Copper sulfate and zinc sulfate (A.R) were used for the preparation of stock $\mathrm{Cu}$ (II) and $\mathrm{Zn}$ (II) solutions respectively. Calcium sulfate and magnesium sulfate were used for ion competition experiment. $\mathrm{pH}$ adjustment was done with hydrochloric acid and sodium hydroxide solutions where necessary.

\section{Adsorbent preparation}

Bamboo stems used for this study were collected from a colony located within the vicinity of the Federal University of Technology Akure Nigeria.

They were shreded into bits, washed with de-ionized water, and oven dried at temperatures $100-105{ }^{\circ} \mathrm{C}$ for about 3 hours to ensure proper drying. The dried materials were then ground using a Victoria grain mill and the granule were made to pass through $850 \mu \mathrm{m}$ sieve.

About $100 \mathrm{~g}$ of the shoot biomass was washed twice with $0.01 \mathrm{M}$ dilute hydrochloric acid by vortexing to remove any form of debris or soluble bio-molecule that might interact with the metal ion. This was centrifuged at $760 \mathrm{rpm}$ for 20 minutes to obtain pellets after each wash. The washed residues were collected and dried in the oven at $100-105{ }^{\circ} \mathrm{C}$ (Gardea-Torresday et al., 1998). They were used for subsequent batch sorption studies. All experiments were conducted in triplicates and the mean values have been reported.

\section{pH profile studies}

Portions of the biomass were weighed separately into beakers, suspended in deionized water to obtain concentrations of 5 
$\mathrm{mg}$ of biomass per $\mathrm{mL}$ solution and stirred for homogeneity. Suspensions in the various beakers were designated for different $\mathrm{pH}$ values. Aliquots of $2 \mathrm{~mL}$ were transferred from the suspensions to clean test tubes each time the $\mathrm{pH}$ value was adjusted, centrifuged and the supernatants discarded.

Metal solutions to be investigated $(0.1$ mmol, $2 \mathrm{~mL}$ ) and of a corresponding $\mathrm{pH}$ were prepared and transferred to test tubes containing the biomass and equilibrated. After two hours, the test tubes were centrifuged and the supernatants transferred to clean sample bottles for metal analysis.

\section{Time dependence study}

Solutions of $50 \mathrm{ml}$ each containing concentrations of $5 \mathrm{mg}$ of biomass per $\mathrm{ml}$ suspension in designated beakers were prepared. The $\mathrm{pH}$ was adjusted to 5.0, suspensions were centrifuged at $760 \mathrm{rpm}$ for 15 mins and the supernatant discarded. The biomasses were re-suspended under continuous stirring onto $50 \mathrm{~mL}$ of $0.1 \mathrm{mmol}$ metal solution previously adjusted to $\mathrm{pH} 5$. Aliquots of the stirred suspensions were collected from designated beakers and transferred to clean test tube at time intervals of $5,10,15,30,60,90$ and 120 minutes. The test tube samples were centrifuged and the supernatant transferred to clean sample tubes for analysis.

\section{Adsorption capacity studies}

Sorption capacity study was conducted for 10 capacity cycles using the biomass (concentration of $5 \mathrm{mg}$ of per $\mathrm{mL}$ of metal solution) and $0.1 \mathrm{mmol}$ of metal solution all at $\mathrm{pH}$ 5.0. Metal solutions were transferred to test tubes containing the biomass and the suspension was equilibrated in a rocker for 30 minutes. After the equilibration it was centrifuged and the supernatant collected in sample tubes for analysis marking the end of one capacity cycle. Fresh metal solution was added to the same biomass and equilibrated for another 30 minutes, centrifuged and withdrawn for analysis.

\section{Calcium and magnesium ion competition study}

Solutions of competing ions (calcium and magnesium) were also prepared for the following concentration; $0.0 \mathrm{mM}, 0.1 \mathrm{mM}, 0.2$ $\mathrm{mM}, 1.0 \mathrm{mM}, 2.0 \mathrm{mM}, 10 \mathrm{mM}, 20 \mathrm{mM}, 0.1$ $\mathrm{M}, 0.2 \mathrm{M}$ and $1.0 \mathrm{M}$. With the $\mathrm{pH}$ of all solutions and biomass adjusted to $5.0,2 \mathrm{~mL}$ of the studied metal solutions and $2 \mathrm{~mL}$ of the calcium concentrations or magnesium concentrations separately for each study were added to the test tube containing $10 \mathrm{mg}$ of the biomass. The mixtures were allowed to react for one hour, preventing the suspension from setting by intermittently swirling each mixture on a Heldoph vortexing machine. The samples were then centrifuged at $760 \mathrm{rpm}$ for 15 minutes and the supernatants for the pellets were transferred to clean sample bottles.

\section{Immobilization of the biomass}

Sample biomass (5 g) was washed twice with water by vortexing and centrifuging for 15 minutes. $75 \mathrm{~mL}$ of $5 \%$ $\mathrm{H}_{2} \mathrm{SO}_{4}$ was mixed with enough $6 \%$ sodium silicate $\left(\mathrm{Na}_{2} \mathrm{SiO}_{3}\right)$ solution to raise the $\mathrm{pH}$ to 2.0. Washed biomass was added to the silica solution and stirred for 15 minutes. The $\mathrm{pH}$ was then raised slowly to 7.0 by adding drop wisely $6 \% \mathrm{Na}_{2} \mathrm{SiO}_{3}$. The polymer gel formed was washed with enough water and later dried over night at $60{ }^{\circ} \mathrm{C}$. This was then ground and passed through a $20-40$ mesh size sieve.

\section{Column experiment}

Approximately $6 \mathrm{~mL}$ of the silicaimmobilized biomass were packed in a column. Prior to passing the metal solution through the column, the immobilized biomass was buffered to the required $\mathrm{pH}$ by passing several bed volumes (volume of the polymer in the column) of $0.01 \mathrm{M}$ sodium acetate (at the optimum binding $\mathrm{pH}$ ) through the column until the effluent obtained was at that $\mathrm{pH}$ (biomass conditioning). Fifty bed volumes of $0.1 \mathrm{mM}$ metal solution prepared in $0.01 \mathrm{M}$ sodium acetate at optimum binding $\mathrm{pH}-5$ were passed through the column at a flow rate of 2 $\mathrm{mL}$ per minute. One bed volume, equivalent 
to approximately $6 \mathrm{~mL}$, were collected in each test tube and analyzed for metal content.

\section{Metal ion recovery from immobilized biomass}

The metal accumulated in the silicaimmobilized biomass was recovered by passing $0.1 \mathrm{M} \mathrm{HCl}$ through the column of immobilized biomass at a flow rate of $2 \mathrm{~mL}$ per minute. Ten bed volumes of the resulting effluent were collected and analyzed for metal content.

\section{Biosorption data analysis}

Copper and Zinc content in the samples was analyzed using Perkin Elmer model 3110 atomic absorption spectrometer. A calibration curve was obtained with a correlation coefficient greater than 0.98 and the instrument response was checked regularly with known standard.

The quantity of $\mathrm{Cu}^{2+}$ and $\mathrm{Zn}^{2+}$ adsorbed by the biomass (qt) in $\mathrm{mg}^{-\mathrm{g}^{-1}}$ was computed using equation (1)

$\mathrm{qt}=(\mathrm{Co}-\mathrm{Ce}) \mathrm{V} / \mathrm{m}$

Where Co is the initial metal concentration, $\mathrm{Ce}$ the final metal concentration in the solution; $\mathrm{V}$ is the volume of the metal solution used in liter (L) and $\mathrm{m}$ is the mass of the adsorbent $(\mathrm{g})$.

\section{RESULTS AND DISCUSSION Influence of initial pH}

$\mathrm{pH}$ is an important parameter on biosorption of metal ions from aqueous solution because it affects the solubility of these ions. As shown in Figure 1 the uptake of $\mathrm{Cu}$ (II) and $\mathrm{Zn}$ (II) depends on $\mathrm{pH}$, increasing from 1 to 5 . Maximum percentage removal of copper was observed at $\mathrm{pH} 5$ with about $26 \%$ increase from the 75 percent copper removed at $\mathrm{pH} 1$. As the $\mathrm{pH}$ values increased however beyond 5, the percent metal removed decreased significantly. This biomass showed a remarkable performance for removing zinc from the solution. At the lowest $\mathrm{pH} \mathrm{1,86}$ percent of the metal was removed and this gradually increased up to $\mathrm{pH} 5$. Zinc sorption remained almost constant, relatively slow up to $\mathrm{pH} 7$ with over 97.8 percent removal. Zinc is amphiprotic hence its indifference to $\mathrm{pH}$ changes.

In all the cases, the pH 5 was considered optimum and used for subsequent investigations. Generally it was clear that the sorption of heavy metal ions significantly decreased at lower $\mathrm{pH}$ values. This is ascribable to the hydrogen ion competing with metal ions for sorption sites (Low and Lee, 2000). At higher $\mathrm{H}^{+}$concentration, the biosorbent surface becomes more positively charged, thus reducing the attraction between adsorbent and metal ions (El-Ashtoukhy et al., 2008). As pH increases, more negatively charged surface become available, thus facilitating greater metal uptake (Chang et al., 1997). At pH higher than 6.0 most heavy metals ions tend to form precipitates which limits the adsorption process considerably. This is witnessed in copper where adsorption could be masked by precipitation (Wang and Xing, 2002).

\section{Effects of contact time}

The copper and zinc up take by the biomass at different contact times has been shown in Figure 2. An ideal biosorbent should rapidly adsorb high concentration of the heavy metals. This is evident from the result of the study conducted using Bambuseae vulgaris biomass. Sorption of $\mathrm{Cu}$ and $\mathrm{Zn}$ by this biomass was very rapid with about $90 \%$ and 99\% uptake respectively within the first five minutes of interaction. This not withstanding, contact time of 120 minutes was investigated. Sorption of copper subsequently increased to $95 \%$ at 15 minutes and gradually dropped to about $88 \%$ at 120 minutes. The optimum adsorption time for copper using this biomass is at 15 minutes. It is note worthy the fact that between the $10^{\text {th }}$ minute and the $120^{\text {th }}$ minute, there could be interplay of adsorption and desorption of the bound metal ions by the biomass. Unlike copper, zinc sorption remained relatively the same throughout the duration of the study ranging from $99.38 \%$ at 5 minutes to $98.92 \%$ at the $120^{\text {th }}$ minute. Very high initial uptake of $\mathrm{Cu}$ had been reported by, 
(Alpana et al., 2007) using filamentous fungus Rhizopus Oryzae and non-living Spirogyra neglecta respectively. It had also been reported that about $75 \%$ removal of $\mathrm{Zn}$ was achieved within the first 10 minutes of contact with carrot residues (Nasernejad et al., 2005). Rapid biosorption indicates that passive surface sorption may occur on the biomass cells. The advantage of such rapid sorption is that smaller reactor volumes can be used (AlRub et al., 2006).

\section{Kinetics of copper and zinc sorption:}

Various adsorption kinetic models have been adopted to describe the behaviour of batch biosorption processes under different experimental conditions. In this work, kinetics of Copper and Zinc sorption was modelled using the pseudo first order and second order equation of Lagergren. As reported by Low and Lee (2000), pseudo-first order reaction of lagergren for sorption can be expressed as

$\mathrm{d}_{\mathrm{q}} / \mathrm{d}_{\mathrm{t}}=\mathrm{K}_{1}\left(\mathrm{q}_{\mathrm{eq}}-\mathrm{q}_{\mathrm{t}}\right)$

Where $\mathrm{q}_{\mathrm{eq}}$ and $\mathrm{q}_{\mathrm{t}}$ are the amount of metal adsorbed per unit weight $(\mathrm{mg} / \mathrm{g})$ of biosorbent at equilibrium and at any time $\mathrm{t}(\mathrm{min}) . \mathrm{K}_{1}$ is the rate constant of pseudo - first order sorption $\left(\mathrm{min}^{-1}\right)$. Integrated form of the above equation yields

$\log \left(\mathrm{q}_{\mathrm{eq}}-\mathrm{q}_{\mathrm{t}}\right)=\log \mathrm{q}_{\mathrm{eq}}-\left(\mathrm{K}_{1} / 2.303\right) \mathrm{t}$

The rate constant for first order reaction $\mathrm{K}_{1}$ can be obtained by plotting $\log \left(\mathrm{q}_{\mathrm{eq}}-\mathrm{q}_{\mathrm{t}}\right)$ versus $t$. Linear plots having high values of coefficient correlation $\left(\mathrm{R}^{2}\right)$ are indicative of the applicability of this kinetic model. As can be seen from Figure 3, rate constant $\mathrm{K}_{1}$ and coefficient of correlation for Copper and zinc, were negative. In applying Lagergren models, experimental equilibrium uptake of copper and zinc should tally with the estimated value (Table 1). In both cases the estimated values were much smaller than the equilibrium uptake values. This model assumes that rate controlling steps for uptake is due to boundary layer resistance. The major disadvantage is that in most of the cases, pseudo first order Lagergren equation does not fit well for experimental data over the entire range of contact time.
Pseudo-second order reaction of Lagergren is expressed as $\mathrm{d}_{\mathrm{q}} / \mathrm{d}_{\mathrm{t}}=\mathrm{K}_{2}\left(\mathrm{q}_{\mathrm{eq}}-\mathrm{q}\right)^{2}$

Where $\mathrm{K}_{2}\left(\mathrm{gmg}^{-1} \cdot \mathrm{min}^{-1}\right)$ derivable from the plot of $\mathrm{t} / \mathrm{qt}$ versus $\mathrm{t}$ is the rate constant for pseudo-second order sorption. The integrated form of this equation is represented as

$\mathrm{t} / \mathrm{qt}=1 / \mathrm{K}_{2}+\mathrm{t} / \mathrm{qe}$

Pseudo-second order rate constant $\mathrm{K}_{2}$ and $\mathrm{q}_{\mathrm{eq}}$ can be calculated from the slope and intercept of the linear plot. The main assumptions of pseudo - second order kinetic model is that rate limiting steps may be chemical sorption involving forces through sharing or exchange of electrons between the metal ions and the biomass. Uptake of copper and zinc by Bambuseae vulgaris as examplified by Figure 4 follows a pseudo second order pattern. It is evident from this plot with correlation factors $\left(\mathrm{R}^{2}\right)$ of 0.9999 for copper and zinc respectively that the sorption reactions followed Lagergren second order model. Estimated values of qe $(\mathrm{mg} / \mathrm{g})$, fall well within the range of the experimental data with very high values of coefficient of correlation. This indicates that the ratecontrolling step of uptake process could be governed by chemisorption process. Sorption kinetics are however controlled by different steps including solute transfer to the sorbent particle surface, transfer from the sorbent particle surface to the intra particle active sites and retention on these sites via sorption, complexation and intra particle precipitation phenomena. Contribution of intra particle diffusion mechanism can be tested by applying the Weber and Morris equation (AlRub et al., 2006; Oliveira et al., 2005). $\mathrm{qt}=\operatorname{Kid~t}^{0.5}$

According to the equation, for intra particle diffusion mechanism, the plot of qt versus $\mathrm{t}^{0.5}$ should be linear. $\mathrm{qt}$ is the amount of solute adsorbed $(\mathrm{mg} / \mathrm{g})$ at time $\mathrm{t}\left(\mathrm{min}^{-1}\right)$. Figure 5 shows that for both metals, the plots are not linear; more so do not pass through the origin. When extrapolated from origin, the initial steep-sloped portion (from 0-5minutes) is attributed to external surface adsorption or instantaneous adsorption. This reveals that the 
intra particle diffusion is rate-controlled and could not be the only mechanism involved (Jain, 2001).

\section{Adsorption capacity}

With a view of establishing the carrying capacity of this biomass, it became necessary to conduct the adsorption capacity experiments. Presented in Figure 6 is the plot of percentage metal bound in a 10 cycle model. Copper (II) ions at Cycle 1 were about $94 \%$ bound. As should be expected, the amount of metal attaching to the biomass is bound to decrease with the number of cycles increasing. This is made manifest with the gradual drop till about $49.42 \%$ at the 10th cycle. The value obtained at cycle 1 tallies with the amount of copper bound in the $5^{\text {th }}$ minute of the time dependency study. Certainly the reason for this high attachment is due to the biomass having maximum binding sites available for interaction at this stage. It has been suggested that two different sorption processes, physic-sorption followed by fast ion exchange then chemisorption could be responsible for the metal binding (Iqbal et al., 2002). As the binding sites get filled up, the amount of metal bound decreases. It should be noted that the fact that this biomass could withstand 10 cycles and yet could remove as much as $50 \%$ of copper is an indication of its viability as a good source of material for water treatment purposes. The efficiency of this biomass to remove zinc was further shown in this experiment. Cycle 1 gave $99.80 \%$ removal rate, a figure that also tallies with the initial 5 minutes result of the time dependency study. Even at the $10^{\text {th }}$ cycle $79.85 \%$ of zinc was still removed. Though our investigation was for 10 cycles there is no doubt that the biomass could take more cycles and yet remain viable.

\section{Interference studies}

Results of the experiments to determine the effect of cation interference on sorption of the investigated Bambusae biomass showed that there is a decline in the ability of the biomass to bind all the metal ions in aqueous solution (Figure 7). The concentration of the introduced cations impacted negatively on the removal process as there is a remarkable reduction in percentage metal bound with increase in concentration of each cation added. Introduction of magnesium caused Zinc sorption to drop from $99.85 \%$ to $91 \%$ while Copper dropped from $95.99 \%$ to $69.47 \%$ at the same interference concentrations. Interference of magnesium not with-standing, the biomass showed capacity for metal removal even when $1 \mathrm{M}$ of the interfering ion coexisted with the metals in solution. Likewise, Calcium interference was also investigated but there was no exceptional difference from that observed in magnesium interference apart from the fact that at the 1molar concentration the percentage metal bound were reduced by between $1 \%$ and $4 \%$. Copper dropped from $95.99 \%$ to 67.74 and zinc from $99.85 \%$ to $88.09 \%$. Decrease in sorption can by explained on the basis of competing $\mathrm{Ca}^{2+}, \mathrm{Mg}^{2+}$ ions for metal binding sites in the biomass. The presence of $\mathrm{SO}_{4}{ }^{2-}$ ions could as well lead to formation of sulphate complexes consequently decrease in free metal ions in solution.

\section{Sorption isotherms}

Since the study was on a single concentration of the heavy metals, sorption isotherms were investigated on the basis of the presence of the various concentrations of the interfering cations. Both the Langmuir and Freundlich models were used to describe adsorption isotherm. Langmuir isotherm for the cation interference on copper and zinc is presented in Figure 8. It can be deduced that adsorption process of the bamboo biomass for the metals investigated followed Langmuir's preposition of a monolayer adsorption procedure. If this result is to be related to intra particle diffusion study then it will be concluded that the process of metal removal by this biomass may involve other processes such as complexation and other intra particle activities. On the basis of this assumption, Langmuir (1916) gave the final form of the model as $\mathrm{q}_{\mathrm{e}}=\mathrm{Q}^{\circ} \mathrm{bC}_{\mathrm{e}} / 1+\mathrm{bC}_{\mathrm{e}}$ 
where $\mathrm{Q}^{\circ}$ and $\mathrm{b}$; the Langmuir constants are the saturated monolayer sorption capacity, and the sorption equilibrium constant, respectively. These parameters were determined for the sorption of copper and zinc on Bambuseae vulgaris from the slope and intercept of the linear plot of $\mathrm{C}_{\mathrm{e}} / \mathrm{q}_{\mathrm{e}}$ versus $\mathrm{C}_{\mathrm{e}}$. The linearized form of equation (7) and their values together with the correlation coefficient, $R^{2}$ are presented in Table 2. The values of $\mathrm{R}^{2}$ (approximately 0.99 ) indicate that the Langmuir model fits better than the Freundlich equation and can be used to describe the biosorption of copper and zinc on this biomass.

Table 1: Adsorption parameters of Lagergren pseudo-first order and pseudo-second order kinetic models.

\begin{tabular}{|c|c|c|c|c|c|c|c|}
\hline \multirow[t]{2}{*}{ Biomass } & \multicolumn{3}{|c|}{ Pseudo-first-order model } & \multirow{2}{*}{$\frac{\text { Experimental }}{\mathrm{qe}(\mathrm{mg} / \mathrm{g})}$} & \multicolumn{3}{|c|}{ Pseudo-second- order kinetic model } \\
\hline & $\mathrm{qe}(\mathrm{mg} / \mathrm{g})$ & $\mathrm{K}_{1}\left(\min ^{-1}\right)$ & $\mathrm{R}^{2}$ & & $\mathrm{qe}(\mathrm{mg} / \mathrm{g})$ & $\mathrm{K}_{2}(\mathrm{~g} / \mathrm{mg} \cdot \mathrm{min})$ & $\mathrm{R}^{2}$ \\
\hline Copper & -0.0012 & -1.02 & -0.09 & 1.2096 & 0.8912 & -0.7237 & 0.9999 \\
\hline Zinc & -0.0015 & -1.93 & -0.05 & 1.3050 & 0.7730 & -0.0970 & 0.9998 \\
\hline
\end{tabular}

Table 2: Sorption isotherm parameters for biosorption of copper and zinc by bamboo biomass.

\begin{tabular}{lccccc}
\hline Model & Parameter & \multicolumn{2}{c}{ Copper } & \multicolumn{2}{c}{ Zinc } \\
\cline { 3 - 6 } & & $\mathbf{M g}$ & $\mathbf{C a}$ & $\mathbf{M g}$ & Ca \\
\hline Langmuir & $\mathrm{Qo}(\mathrm{mg} / \mathrm{g})$ & 0.8702 & 0.8385 & 1.1495 & 1.1109 \\
& $\mathrm{~b}(\mathrm{~L} / \mathrm{mg})$ & 0.1135 & 0.1397 & 0.0188 & 0.0299 \\
\hline \multirow{3}{*}{ Freundlich } & $\mathrm{R}^{2}$ & 0.9965 & 0.9958 & 0.9880 & 0.9950 \\
& $\mathrm{~K}_{\mathrm{f}}$ & -7.004 & -5.796 & -41.16 & -26.946 \\
& $\mathrm{n}$ & 0.0627 & 0.0967 & 3.244 & 1.7712 \\
& $\mathrm{R}^{2}$ & -0.9660 & -0.9589 & -0.8898 & -0.8584 \\
\hline
\end{tabular}

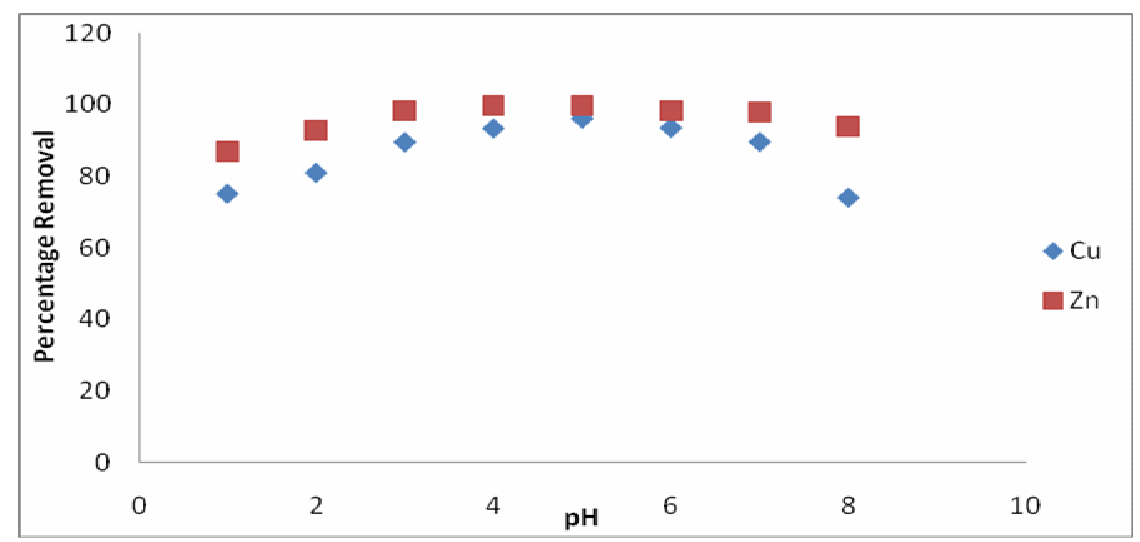

Figure 1: Effect of $\mathrm{pH}$ on sorption. 


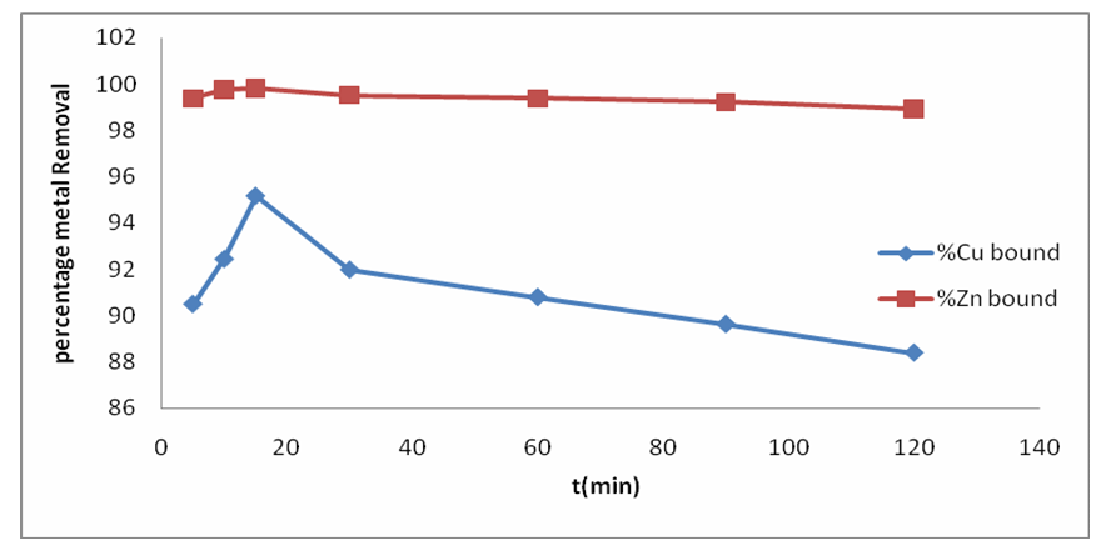

Figure 2: Percentage metal bound as a function of contact time.

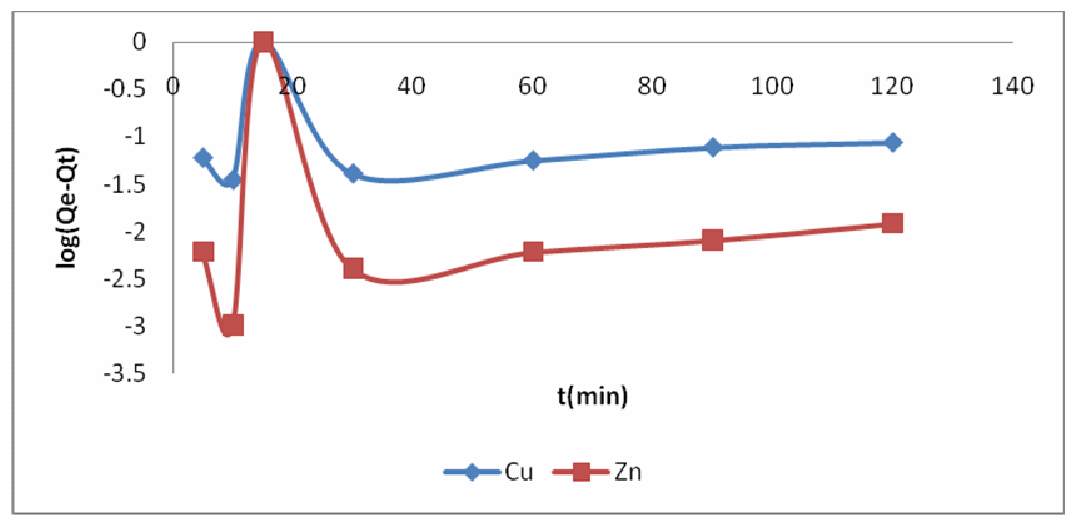

Figure3: Lagergren pseudo-first order reaction.

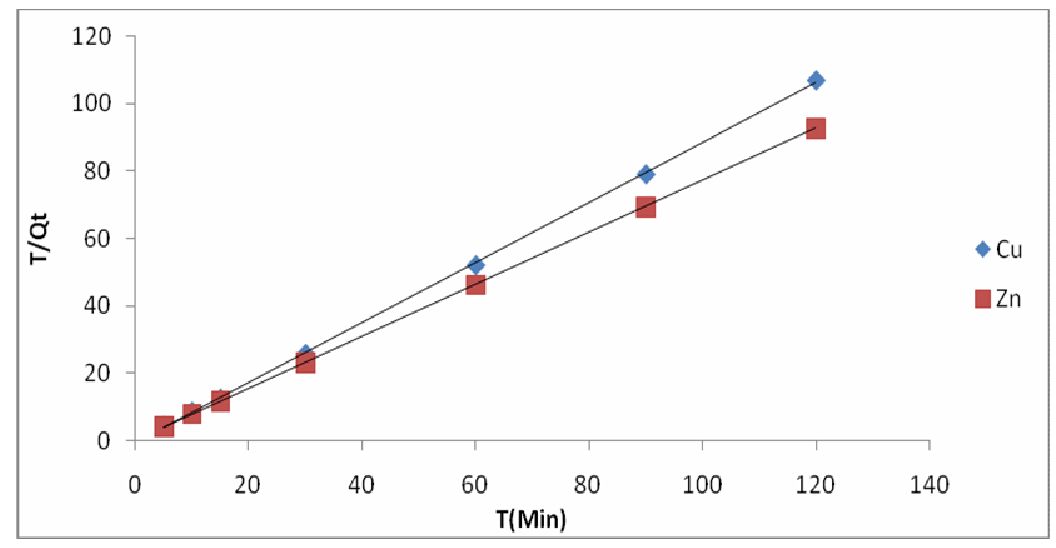

Figure 4: Lagergren second order reaction. 


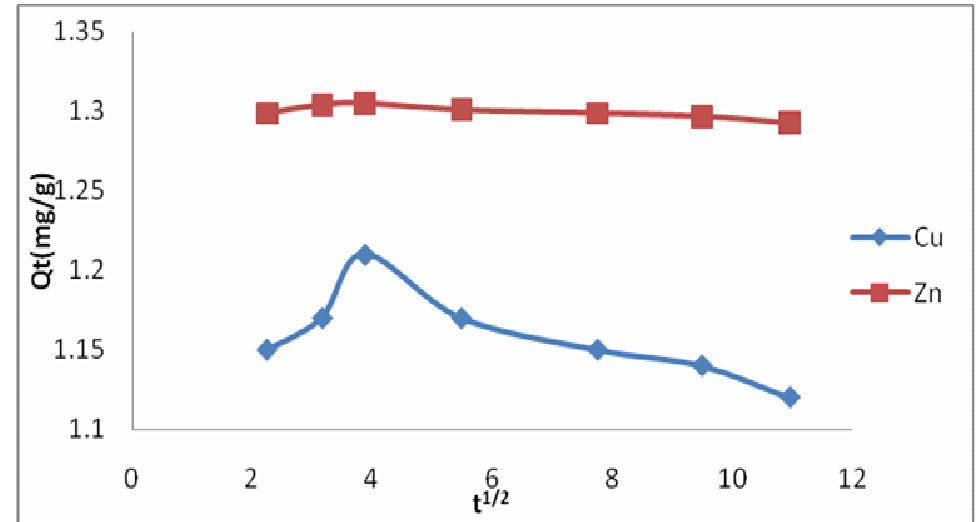

Figure 5: Intraparticle diffusion.

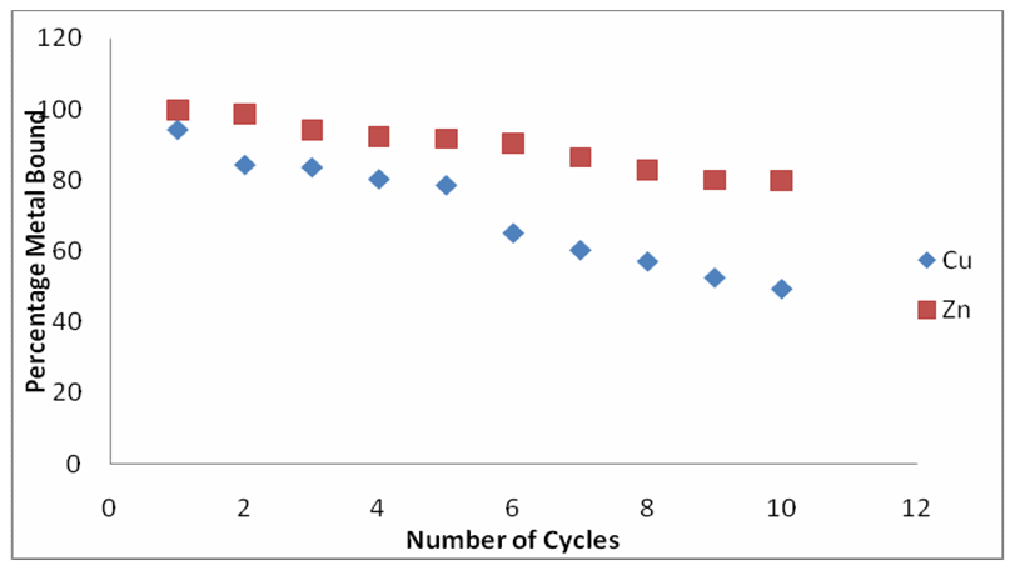

Figure 6: Plot of the percentage metal bound versus number of cycles.

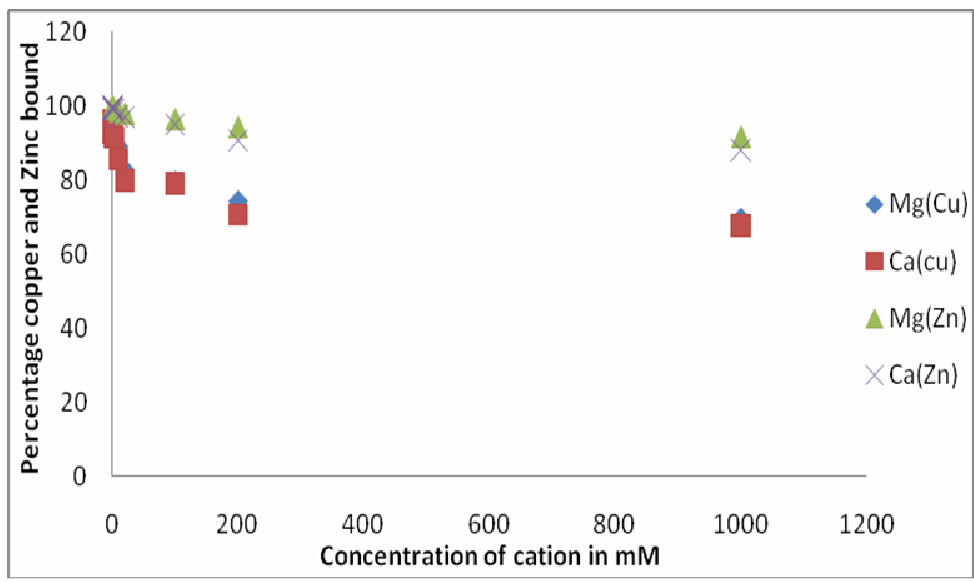

Figure 7: Effect of concentration of interfering ions on percentage metal removal. 


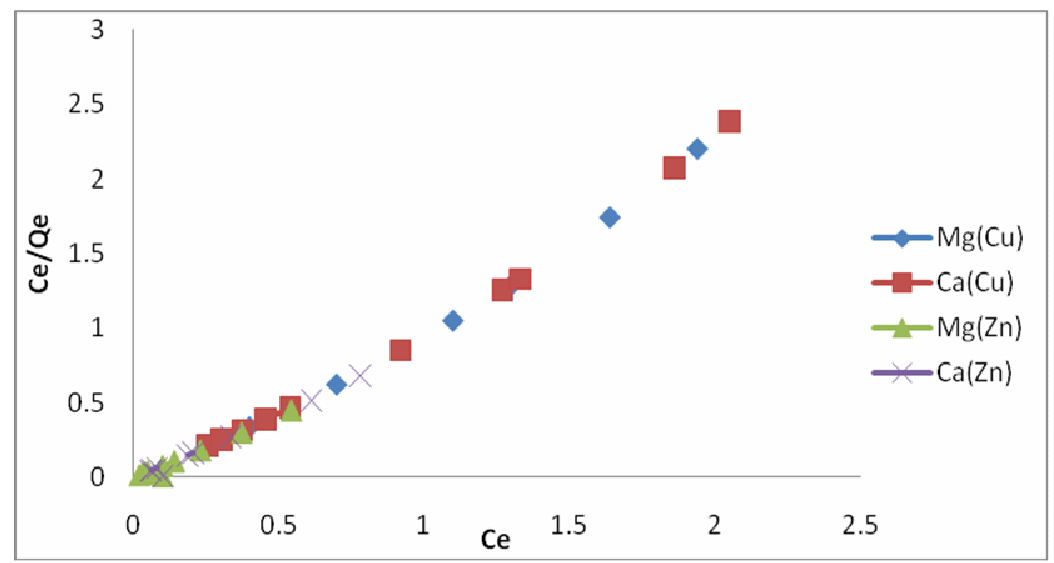

Figure 8: Langmuir sorption isotherm for $\mathrm{Cu}^{2+}$ and $\mathrm{Zn}^{2+}$ based on cátion.

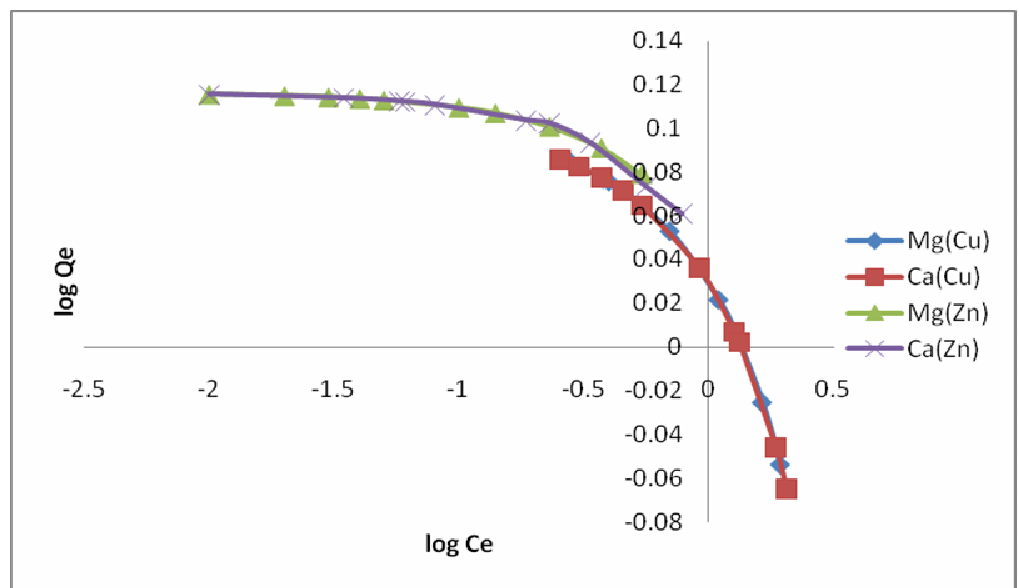

Figure.9: Freundlich sorption isotherm for $\mathrm{Cu}^{2+}$ and $\mathrm{Zn}^{2+}$ based on cation interference.

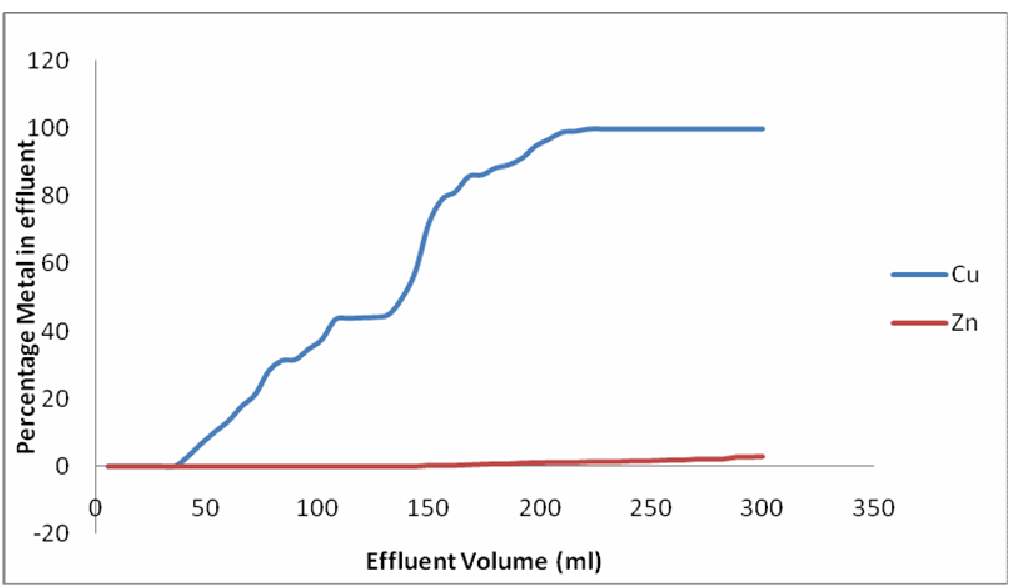

Figure 10: Percentage metal bound relative to effluent volumes. 
This finding also predicts the heterogeneity of the adsorption sites on adsorbent surface (Gode and Pehlivan, 2006; Gode, 2007). Although the saturated monolayer sorption capacity, $\mathrm{Q}^{\circ}$, is a function of many parameters such as $\mathrm{pH}$ and temperature, it provides a good measure for comparing the efficiency of different sorbents in removing a given metal (Abu Al-Rub et al., 2004).

Freundlich isotherm, which is applied to non-ideal sorption on heterogeneous surfaces and also to a multilayer sorption, suggests that binding sites are not equivalent or independent (Oliveira et al., 2005). The logarithmic form of the equation is

Log qe $=\log \mathrm{K}_{\mathrm{f}}+1 / \mathrm{n} \log \mathrm{Ce}$

Where $K_{f}$ indicates the adsorption capacity and $1 / n$ is the sorption intensity. $K_{f}$ and $n$ can be derived from the plots of log qe versus log Ce which ought to be linear.

It can also be deduced from these tests that Freundlich isotherm for cation interference on copper and zinc respectively which are represented in Figure 9 has not been obeyed. In areas where a linear plot could possibly be extrapolated, the correlation coefficient appears lower than the plots obtained for Langmuir isotherm.

\section{Column experiment}

In a breakthrough curve, the concentration of a given species in the effluent is plotted against the bed volume of the target solution (in this experiment, 1 bed volume was equal to $6 \mathrm{ml}$ ). Figure 10 shows the breakthrough curve obtained when the silica-immobilized biomass packed column was treated with the $0.1 \mathrm{mM} \quad \mathrm{Cu}(\mathrm{II})$ and $\mathrm{Zn}(\mathrm{II})$ solutions respectively. It can be seen that the immobilized biomass had a higher affinity to $\mathrm{Zn}$ than for $\mathrm{Cu}$. Zinc showed $100 \%$ removal rate after 24 bed volumes had been passed through the column. The biomass however had a strong potency in binding the metals up to the $50^{\text {th }}$ bed volume. Results presented show that at the last bed volume of our study the biomass could retain as much as $97 \%$ of the zinc passing through. Perhaps the same biomass could accommodate more bed volumes of zinc concentration before getting exhausted. Plot of $\mathrm{Cu}^{2+}$ effluent concentration exhibited the typical ' $S$ ' shaped curve of a fixed bed-column (Mehta, 2005). Removal efficiency $(100 \%)$ could only be guaranteed for 6 bed volumes. Thereafter there is a steep decline up to bed volume 20 when about $40 \%$ of the metal was found in the effluent. Between bed volumes 20 and 25 the binding rate appeared to normalize at a little below $60 \%$ thereafter it further dropped to $20 \%$ at bed volume 29 . Subsequently $0 \%$ removal was obtained beyond the $35^{\text {th }}$ bed volume when $200 \mathrm{ml}$ of the metal had passed through.

\section{Metal recovery}

Desorption of the metals bound to the bamboo biomass was effected by eluting with $0.1 \mathrm{M} \mathrm{HCl}$. Results of metal analysis of the effluent after passing 10 bed volumes of 0.1 $\mathrm{M} \mathrm{HCl}$ showed that $99 \%$ of bound copper was recovered from the biomass. Zinc recovery was however low. Only about $10 \%$ of the bound Zinc was recovered thus confirming that binding affinity of zinc to this biomass is very high. It is very possible that high concentrations of the acid will have positive effect in desorption of zinc.

\section{Conclusion}

This study investigated the potential use of Bamboo biomass for the removal of copper and zinc from contaminated water. The biosorption of both metals on the biomass was rapid given that over $90 \%$ of the metals were removed within the first 5 minutes of interaction and was found to follow pseudosecond order kinetic model. It was observed that $\mathrm{pH}$ played prominent role in the adsorption process. The presence of magnesium and calcium interfering ions reduced the binding efficiency of copper and zinc especially at higher concentrations of these interfering ions. Biosorption of the metals at different concentrations of the interfering ions could be fitted to the Langmuir and Freundlich isotherm models. The biosorption of the metals on the biomass 
is by a combination of ion exchange, electrostatic interactions, surface complexation and intra-particle diffusion mechanisms.

The immobilization of the bamboo biomass showed remarkable ability in the removal of these metals from aqueous solution in fixed-bed column experiment. Recovery efficiency of the bound copper is equally high eluting with $0.1 \mathrm{M}$ solution of $\mathrm{HCl}$.

\section{REFERENCES}

Abu Al-Rub FA, El-Naas MH, Benyahia F, Ashour I. 2004. Biosorption of nickel on blank algianata bead, free and immobilized algal cell. Proc. Biochem., 39: 1767-73.

Ahluwalia SS, Goyal D. 2007. Microbial and plant derived biomass for removal of heavy metal from waste water. Bioresource Technology, 98(12): 22432257

Aksu Z. 2001. Equilibrium and Kinetic modeling of cadmium (II) biosorption by C. Vulgaris in a batch system: effect of temperature. Sep. Purif. Technol., 21: 285-94.

Alpana S, Dhanajay K and Gaur JP. 2007. Copper (II) and Lead (II) sorption from aqueous solutions by non-living spirogyra neglecta; Bioresource Technology, 98: 3622-13629.

Bailey SE, Olin J J, Bricka RM and Adrian DD. 1999. A review of potentially low cost sorbents for heavy metals. Water Res., 33: 2469-79.

Chang J, law R, Chang C. 1997. Biosorption of lead, copper and cadmium by biomass of pseudomonas acruginosa. Water Res., 31: 1651-1658.

El- Ashtoukhy ESZ, Amin NK, Abdelwahab O. 2008. Removal of lead (II) and copper (II) from aqueous solution using pomegranate peel as a new adsorbent. Desalination, 223: 162-173.

Fengel D, Shao X. 1984. A chemical and ultra structural study of the bamboo species phytostachys Makinoi Hay. Journal of
Wood Science and Technology, 18(2): 102-112.

Figueira MM, Volesky B, Ciminelli VST, Roddick. 2000. Biosorption of metal in brown seed biomass. Water Res., 34: 196204.

Gardea-Torresday JL, Tiemann KJ, Hernandez A, Rodriguez O, Sias S. 1998. Enhanced metal binding capacity of $\mathrm{NaOH}$ treated Larrea-Tridentata leaf tissue. Proceeding of the Conference on Hazardous Waste Research, pp.101-110.

Gode F, Pehlivan E. 2006. Removal of Cr(III) from aqueous solutions using Lewatit $\mathrm{S}$ 100: the effect of $\mathrm{pH}$, time, metal concentration and temperature. Journal of Hazardous Materials, 136(2): 330-337.

Gode F, Pehlivan E. 2007. Sorption of Cr(III) onto chelating b-DAEGsporopollenin and CEP-sporopollenin resins. Bioresource Technology, 98: 904-911.

Iqbal M, Saeed A, and Akhtar N. 2002. Petriolar Felt - Sheath of Palm: A new Biosorbent for the Removal of Heavy Metals from Contaminated Water. $J$. Bioresource Technology, 81: 151-153.

Jain CK. 2001. Adsorption of zinc onto bed sediments of ... Hydrological Sciences Journal - des Sciences Hydrologiques, 46(3): 419.

Keshkinkan O, Goksu MZL, Yuceer A, Basibuyuk M, Forster CF. 2003. Heavy metal adsorption characteristics of a submerged aquatic plant (myriophylhum spicatum). Process Biochemistry, 39: 179-183.

Kuyucak N, Volesky B. 1989. The mechanism of cobalt biosorption. Biotech. Bio Eng., 33: $823-831$.

Larous S, Meniai AH, Bencheikh Lechocine M. 2005. Experimental study of the removal of copper from aqueous solutions by adsorption using sawdust. Desalination, 185: 483-490.

Low SK, Lee CS. 2000. Sorption of cadmium and lead from aqueous solutions by spent grain. Process Biochem., 36: 59 -64.

Magat HM, Ibrahim SC, Yahya MZA. 2006. Equilibrium adsorption study of lead ions 
onto sodium hydroxide modified Lalang (imperata cylindrical) leaf powder. Journal of Applied Science Research., 2(12): 1169-1174.

Mehta SK, Gaur JP. 2005. Usage of algae for removing heavy metal ions from waste water: progress and prospects; Crit. Rev. Biotechnol., 25: 113-152.

Nasernejad B, Esslam Zedeh T, Bonkdar Pour B, Esmaail Bygi M, Zamani A. 2005 Comparison for biosorption modeling of heavy metals ( $\mathrm{Cr}$ (III), Cu (II), Zn (II); adsorption from waste water by carrot residues. Proc. Biochem., 40: 1319-1322.

Okoronkwo AE, Olasehinde EF. 2007. Investigation of lead binding by Tithonia Diversifolia. J. Applied science, 12: 15891595.

Oliveira, EA, Montanher SF, Andrade, AD, Nobrega JA, Rollemberg MC. 2005. Equilibrium studies for the sorption of chromium and nickel from aqueous solutions using raw rice bran. Process Biochem., 40: 3485-3490.
Sharma YC, Prasad G, Rupaniwar DC. 1992. Heavy metal pollution of river Gang in Mirzapur, India international journal of environmental studies section B. Environmental Science and Technology 40: $41-53$.

Sternberg SPK, Dom RW. 2002. Cadmium removal using cladophora in batch, semibatch and flow reactor. Bioresource Technology, 81: 249-55.

Valdman E, Erijman L, Pessoa FLP, Leite S.G.F. 2001. Continuous biosorption of $\mathrm{Cu}$ and $\mathrm{Zn}$ by immobilized waste biomass Sargassum Sp. Proc. Biochem., 36: 869873.

Volesky B. 1994. Advances in biosorption of metals: selection of biomass tupes. FEMS Microbial Rev., 14: 291-302.

Wang K, Xing B. 2002. Adsorption and desorption of cadmium by goethite ... Chemosphere, 48: 665-670. 